\title{
Predicting Nurses' Mental Health Based on Their Job Burnout, Perceived Social Support, and Psychological Hardiness
}

\author{
Nahid Babaeiamiri ${ }^{1, *}$ \\ ${ }^{1}$ Department of Psychology, College of Management and Accounting, Yadegar-e-Imam Khomeini (RAH) Shahre Ray Branch, Islamic Azad University, Tehran, IR Iran \\ "Corresponding author: Nahid Babaeiamiri, Department of Psychology, College of Management and Accounting, Yadegar-e-Imam Khomeini (RAH) Shahre Ray Branch, Islamic \\ Azad University, Tehran, IR Iran. Tel: +98-9125504779, E-mail: nbabaieamiry@yahoo.com
}

Received 2016 February 27; Revised 2016 March 15; Accepted 2016 April 15.

\begin{abstract}
Background: Nurses experience considerable stress due to their difficult working conditions. Experiencing stress over a long period of time can influence mental health.

Objectives: This study aimed at predicting nurses' mental health based on their job burnout, perceived social support, and psychological hardiness.

Methods: This correlational study was done during year 2015 on 400 individuals, who worked in public hospitals located in Tehran, Iran. All nurses completed Maslach and Jackson's job Burnout inventory, Zimet et al.'s Perceived Social support scale, Kobasa's psychological hardiness inventory, and Goldberg and Hillier's general health questionnaire. The data were analyzed using the SPSS software (v. 19.0) through running the Pearson correlation analysis and multiple regression analysis at a significance level of less than 0.01 .

Results: Nurses' mental health was positively correlated with their job burnout $(r=0.37)$ and negatively with their perceived social support $(\mathrm{r}=-0.56)$ and psychological hardiness $(\mathrm{r}=-0.53 ; \mathrm{P}<0.01)$. Job burnout, perceived social support and psychological hardiness explained $54.9 \%$ of the total variance of nurses' mental health $\left(R^{2}=0.549\right)$.

Conclusions: Given the significant role of job burnout, perceived social support and psychological hardiness in predicting nurses' mental health, manipulating these variables can help improve nurses' mental health.
\end{abstract}

Keywords: Job Burnout, Perceived Social Support, Psychological Hardiness, Mental Health, Nurses

\section{Background}

Nursing profession is a demanding and damaging job. Knezevic believed that, nurses carry the highest level of workload compared with other healthcare workers (1). Currently, the importance of health is so important that health authorities have mainly focused on health promotion (2). According to the world health organization, health is not simply the absence of illness; rather, it is a state of physical, mental and social wellbeing (2). General health is defined as complete physical, mental and social health, while mental health is the ability to have harmonious relationships with others, change and improve personal and social environments, and manage personal conflicts and desires so that life becomes meaningful and purposeful (3).

According to Maslach and Jackson (1981) (4), one of the main concepts related to mental health is job burnout. Stress and psychological pressure are inseparable parts of every job, the levels of which vary according to the type of job. Job burnout is a state of physical, emotional, and mental exhaustion, which occurs due to long-term exposure to a demanding job. It is also a response to acute job- related pressures, and is a psychological syndrome that involves emotional exhaustion, depersonalization, and low personal accomplishment. In emotional exhaustion, the afflicted person feels himself/herself being under pressure and losing emotional resources, while in depersonalization, a person becomes indifferent to his/her clients. Moreover, low personal accomplishment describes decreased competence in efficient job performance (5). The findings of previous studies about the relationship of job burnout with mental health are conflicting; for instance, Karanikola and Papathanassoglou (2013) and Salimi et al. (2013) $(6,7)$ reported a negative correlation between these variables. However, Yavari et al. (2014) (8) found that although job burnout of critical care nurses was significantly correlated with their mental health, there was no significant correlation between these two variables among psychiatric nurses.

Another key concept related to mental health is perceived social support (PSS), which is conceptualized as individuals' cognitive evaluation of the amount of support provided to them by the immediate environment and others. Social support theorists believe that not all interpersonal relationships can be considered as social support. In 
other words, relationships are not inherently a source of support unless an individual considers them as a suitable and accessible source for fulfilling his/her needs (9). Sometimes, assistance provided to individuals may be inappropriate, untimely, or against their wills. Consequently, the main point of interest is individuals' perception of support. In other words, social support focuses on individuals' cognitive evaluations of their immediate environment and the level of confidence about the availability of help and support (10).

Perceived Social Support gives individuals a sense of being worthwhile and being a member of a social network and provides them with the opportunity to establish and strengthen their relationships. Social support is also equal to individuals' positive perceptions of family members, friends, and others' kindness, companionship and attention (11). Some studies reported a positive relationship between PSS and mental health $(12,13)$ while Alipor et al. (2011) (14) found that PSS was not significantly correlated with mental health.

According to Kobasa (1979), psychological hardiness is also associated with mental health. Psychological hardiness is a personality trait that acts as a source of resistance in stressful life evens. Individuals with great psychological hardiness can control their life events (15). They also consider their problems as opportunities for development rather than something to avoid. In other words, not only they do not consider themselves as victims of change, but also attempt to be the main determinant of change-related consequences. Hardiness is also effective in maintaining health, functionality, and quality of life in stressful situations (16). Study findings in the area of the relationship between psychological hardiness and mental health are also conflicting. Tarimoradi (2014) and Jafari et al. (2012) $(17,18)$ reported a positive correlation between them while Saxena (2015) (19) found that they did not significantly correlate with each other.

Nursing is a demanding and stressful job and nurses carry the highest level of workload compared with other healthcare workers (1). Heavy workload can gradually undermine nurses' mental health. As nurses are responsible for maintaining and promoting patients' health, assessing and promoting their own health is necessary. Although previous studies have examined the relationship of job burnout, PSS, and psychological hardiness with mental health, their findings are conflicting. One of the obvious shortcomings of previous studies is their failure to assess the collective role of these variables in predicting mental health. In other words, it is unknown which of these variables can provide more accurate information about mental health.

\section{Objectives}

The present study was made to predict nurses' mental health based on their job burnout, PSS and psychological hardiness.

\section{Methods}

This correlational study was performed during year 2015. The study population included nurses who worked in public hospitals located in Tehran, Iran. The number of these nurses was around 47000. Based on the sample size calculation table proposed by Morgan et al., it was determined that 381 nurses were required for the study. Nonetheless, given the probable withdrawal of some nurses from the study, we increased the sample size to 400 . Eligible nurses were recruited in the study through multistage sampling (20). Consequently, the city of Tehran was divided to five northern, southern, eastern, western and central regions from which, three regions were selected through simple random sampling. After that, six hospitals were selected from each region once more through simple random sampling. Finally, 22 eligible nurses were recruited from each hospital. The eligibility criteria included working the morning shift in public hospitals, receiving no psychiatric medication, and experiencing no stressful life events, such as divorce or significant loss during the last six months prior to the study. Nurses, who avoided signing the informed consent form of the study or incompletely filled out their questionnaires, were excluded.

Study data were gathered using the following four questionnaires:

Job burnout was measured through employing Maslach and Jackson's job Burnout inventory (MBI). This inventory contains 22 items, which are scored on a sevenpoint Likert scale from 0 to 6 . Some of the items are scored reversely. The final total score of the inventory is calculated through summing the scores of all items and dividing the sum by the number of the inventory items. Therefore, the final total score ranges from 0 to 6 ; the higher the score, the greater the job burnout. Maslach and Jackson (1981) (4) reported a Cronbach's alpha of 0.87 for the inventory. Moreover, Ahghar (2007)(21) also found that its Cronbach's alpha and test-retest correlation coefficient were 0.90 and 0.88 , respectively. In the present study, the Cronbach's alpha of the MBI was 0.83 .

We also used Zimet et al.'s Perceived Social support scale (PSSS) to quantify the participants' PSS. The twelve items of this scale are scored on a seven-point Likert scale from one to seven, resulting in a total score of one to seven. Higher PSSS scores show higher levels of PSS. Zimet et al. 
(1988)(22) found that the Cronbach's alpha of the scale was 0.92. Souri and Ashoori (2015) (23) also reported a Cronbach's alpha of 0.85 for the scale. The Cronbach's alpha value of the PSSS in our study was 0.88 .

Psychological hardiness was assessed via the 50-item Kobasa's psychological hardiness inventory (PHI), the items of which are scored on a four-point Likert scale from one to four. The final PHI total score is calculated through summing the item scores and averaging the sum score. Consequently, the possible PHI total score would be one to four; the higher the score, the greater the psychological hardiness. The Cronbach's alpha of the PHI has been reported as 0.78 (24) and 0.83 (23). The alpha value in the current study was 0.76 .

The participants' mental health was evaluated by using the Goldberg and Hillier's general health questionnaire (GHQ). The scoring of the 28-item GHQ is performed on a four-point Likert scale from 0 to 4 . The mean score is calculated from the sum score of the questionnaire, resulting in a final total GHQ score of 0 - 4. Higher scores show lower mental health and vice versa. The GHQ has been reported to have a Cronbach's alpha value of 0.84 (25) and 0.91 (26). We also found that the alpha value of the questionnaire was 0.88 .

The ethics committee of Yadegar-e-Imam Khomeini branch of Islamic Azad University, Tehran, Iran, approved the study in October 4, 2015, with the following code 0823.3510. The participants were ensured about the confidential management of their data and their written consent was secured.

The measures of descriptive statistics were used for describing the distributions of the study variables. Moreover, the Pearson correlation analysis and multiple regression analysis were performed using the SPSS software (v. 19.0) for testing statistical hypotheses at a significance level of less than 0.01 .

\section{Results}

The study participants were 400 nurses, who worked in public hospitals located in Tehran, Iran, from whom, 273 nurses $(68.25 \%$ ) were female and 127 (31.75\%) were male. Moreover, 329 nurses (82.25\%) were married, 41 (10.25\%) were single, sixteen (4\%) were divorced, and fourteen were widowed (3.5\%). The frequency distributions of the participants' educational status and monthly family income are depicted in Table 1. Moreover, the maximum, minimum, mean, and standard deviation values of their job burnout, PSS, psychological hardiness, and mental health are shown in Table 2.

The correlation of mental health with job burnout was positive $(r=0.37)$ while its correlation with PSS and psycho-
Table 1. The Frequency Distributions of Nurses' Educational Status and Monthly Family Income $(n=400)$

\begin{tabular}{|cc}
\hline Variables & Frequency (\%) \\
\hline Nurses' educational status & \\
\hline Associate diploma & $47(11 / 75)$ \\
\hline Bachelor's & $319(79 / 75)$ \\
\hline Master's & $34(8 / 50)$ \\
\hline Monthly family income (million Tomans) & \\
\hline$<3.5$ & $29(7 / 25)$ \\
\hline $3.5-4$ & $185(46 / 25)$ \\
$4-4.5$ & $144(36)$ \\
\hline 4.5 & $42(10 / 5)$ \\
\hline
\end{tabular}

logical hardiness was negative $(r=-0.56$ and -0.53 , respectively). Moreover, job burnout was negatively correlated with PSS $(\mathrm{r}=-0.34)$ and psychological hardiness $(\mathrm{r}=-0.29)$. The PSS was also positively correlated with psychological hardiness ( $r=0.31$; Table 3 ).

Multiple regression analysis was performed for predicting mental health based on job burnout, PSS and psychological hardiness (Table 4). These variables could significantly predict $54.9 \%$ of the total variance of the nurses' mental health $\left(\mathrm{R}^{2}=0.549 ; \mathrm{P}<0.0001\right)$. Moreover, job burnout had a significant positive role in predicting mental health $(\beta=0.239 ; \mathrm{P}<0.004)$ while PSS $(\beta=-0.335 ; \mathrm{P}$ $<0.0001)$ and psychological hardiness $(\beta=-0.264 ; \mathrm{P}<$ 0.008 ) played significant negative roles in predicting mental health. The most significant predictive role regarding the nurses' mental health was related to PSS ( $\beta=-0.335$; Table 4).

\section{Discussion}

The findings of the present study revealed a significant correlation between job burnout and mental health. Karanikola and Papathanassoglou (2013) (6) and Salimi et al. (2013) (7) also reported the same findings. However, this finding contradicted the findings reported by Yavari et al. (2014) (8). Increased emotional exhaustion and negative mental energy (i.e. job burnout) can be associated with pessimism (about one's own attempts and even about others), high levels of depression and anxiety, and low personal achievement. On the other hand, low personal accomplishment may be associated with poor mental health. Consequently, high job burnout can undermine nurses' mental health (8).

The contradiction of our findings with the findings reported by Yavari et al. (2014) (8) may be due to the 
Table 2. Description of the Nurses' Job Burnout, Perceived Social Support, Psychological Hardiness, and Mental Health

\begin{tabular}{|c|c|c|c|c|}
\hline Variables & Mean & Standard Deviation & Minimum Value & Maximum Value \\
\hline Job burnout & 3.75 & 0.87 & 0.00 & 4.37 \\
\hline PSS & 4.95 & 1.62 & 1.58 & 5.67 \\
\hline Psychological hardiness & 2.62 & 0.89 & 1.24 & 3.92 \\
\hline Mental health & 1.18 & 0.55 & 0.34 & 2.94 \\
\hline
\end{tabular}

Table 3. The Correlations of Job Burnout, Perceived Social Support, Psychological Hardiness, and Mental Health

\begin{tabular}{lccc}
\hline Variables & $\mathbf{1}$ & $\mathbf{2}$ & $\mathbf{3}$ \\
\hline 1. Job burnout & 1 & & \\
2. PSS & $-0.34^{\mathrm{a}}$ & 1 & \\
3. Psychological hardiness & $-0.29^{\mathrm{a}}$ & $0.31^{\mathrm{a}}$ & 1 \\
\hline 4. Mental health & $0.37^{\mathrm{a}}$ & $-0.56^{\mathrm{a}}$ & $-0.53^{\mathrm{a}}$ \\
\hline${ }^{\mathrm{a}} \mathrm{P}<0.01$. & & &
\end{tabular}

fact that their study was performed on psychiatric nurses while our participants were nurses, who worked in general hospital wards. Due to their stressful working conditions, novice psychiatric nurses experience constant severe stress, reach a state of learned frustration, and develop job burnout. All these conditions undermine their mental health. Nonetheless, they gradually learn and attempt to solve their problems, cope with their conditions, and manage burnout and thus, they feel lower levels of burnout and higher levels of mental health. Accordingly, job burnout cannot significantly affect the mental health of senior psychiatric nurses (8).

In line with the findings reported by Chadwick et al. (2015) (12) and Cheng et al. (2014) (13), our findings also indicated a significant negative correlation between nurses' PSS and mental health. Perceived Social Support helps people feel that they are loved and cared for by others, are valuable and respectful, and belong to a network of people. Strong support and relationship networks enable people cope with environmental pressures and place them in more favorable psychological conditions and hence, improve their mental health. On the other hand, PSS acts as a protective shield against stressful events, reduces feelings of isolation and loneliness, and creates a sense of self-esteem. Besides, it has direct and indirect positive effects on people's cognitive mechanisms and coping strategies. Consequently, people with firmer PSS have more optimistic attitudes towards life, are happier and more hopeful, and hence, have higher levels of mental health.

In contrary to our findings, Alipor et al. (2011) (14) found no significant correlation between PSS and mental health. This contradiction may be due to differences in the samples of the studies in that they conducted their study on females with multiple sclerosis while we performed our study on nurses. Females with multiple sclerosis have special needs and need intensive care services. Primarily, they feel satisfied with the support provided by others. However, they may gradually feel that others support them compulsorily. Therefore, they may not perceive others' support as real support. In other words, although women with multiple sclerosis are usually supported by others, women in the study of Alipor et al. (2011) might have perceived low social support, resulting in an insignificant correlation between PSS and mental health. On the other hand, the positive correlation of PSS with mental health in our study may be due to the fact that nurses, as healthy people, consider others' support as real support and feel satisfied with it (27).

The findings of the present study also indicated a significant negative correlation between nurses' psychological hardiness and mental health. Tarimoradi (2014) (17) and Jafari et al. (2012) (18) also reported the same findings. An explanation for this finding may be the fact that psychological hardiness is a combination of beliefs about self and the world and consists of components such as commitment, control and defiance. Highly committed individuals are aware of the importance and the value of self in doing activities and hence, can successfully perform activities through relying on them self. On the other hand, individuals with high self-control consider life events as predictable and controllable and believe that they can affect events through making personal efforts. Besides, defiant individuals attempt to solve problems and believe that change is a normal aspect of life. Such individuals consider happy and bad events as opportunities for development and learning, rather than threats. Such an approach to life improves flexibility and endurance and enhances mental health. Another explanation for this finding is that individuals with high psychological hardiness have a series of personality traits, which act as a source of resistance in stressful life events. They have greater control on life events and instead of avoiding problems, consider them as opportunities for 
Table 4. The Results of Multiple Regression Analysis for Predicting the Nurses' Mental Health

\begin{tabular}{lcccccc}
\hline Predictors & R & $\mathbf{R}^{2}$ & F Statistics & df & PValue & $\beta$ \\
\hline Job burnout PSS & & & & & & \\
Psychological hardiness & 0.741 & 0.549 & 46.082 & $3 ; 396$ & 0.004 \\
\hline
\end{tabular}

development. Besides, they evaluate stressful events more positively and consider them controllable. Such abilities reduce the severity of physiological arousal and the incidence of stress syndrome and enhance mental health.

Although we found a significant correlation between psychological hardiness and mental health, Saxena (2015) (19) reported that such correlation was not statistically significant. These conflicting findings may be due to the fact that their study was performed on students, who were unemployed and hence, had not experienced work-related challenges. Therefore, they all had the same level of psychological hardiness, resulting in an insignificant correlation between their psychological hardiness and mental health (28). However, we did our study on nurses, whose psychological hardiness had increased due to the experience of providing patient care in challenging situations and thus, they were more competent and empowered and had higher levels of mental health.

Due to its nature, the present study faced several limitations. For instance, data collection using self-report questionnaires might have negatively affected the study results. Another limitation was that the study population was confined only to nurses, who worked the morning shift in public hospitals located in Tehran. Future studies are recommended to study nurses, who work in other shifts and hospitals. Moreover, comparing female and male nurses or nurses of different cities in terms of job burnout, PSS, psychological hardiness, and mental health can be investigated by future studies.

\subsection{Conclusion}

The study findings suggest that job burnout can undermine nurses' mental health while PSS and psychological hardiness can improve it. Therefore, health managers and authorities need to implement empowerment programs in order to enable nurses employ effective strategies for improving their own mental health. Moreover, given the significant correlation of PSS and mental health, nurses' families, friends and significant others need to provide them with strong support. As their friends and significant others, hospital administrators can play significant roles in improving nurses' mental health. In addition, training workshops can be held for alleviating nurses' job burnout and enhancing their psychological hardiness. Such interventions can significantly improve their mental health.

\section{Acknowledgments}

This article came from a research project, approved by Yadegar-e-Imam Khomeini branch of Islamic Azad University, Tehran, Iran. We would like to thank all administrators and nurses working at public hospitals of Tehran, Iran, who supported us during the study.

\section{References}

1. JamshidianGhalehShahi P, Manshaee G, Yaghoobzadeh M. A study of the relationship between humor styles and dimensions of burnout among nurses in Najaf Abad in 2013 [in Persian]. Mod Care J. 2014;11(3):203-10.

2. Rajmil L, Roizen M, Psy AU, Hidalgo-Rasmussen C, Fernandez G, Dapueto JJ, et al. Health-related quality of life measurement in children and adolescents in Ibero-American countries, 2000 to 2010. Value Health. 2012;15(2):312-22. doi: 10.1016/j.jval.2011.11.028. [PubMed: 22433763].

3. McFarland MJ. Religion and mental health among older adults: do the effects of religious involvement vary by gender?. J Gerontol B Psychol Sci Soc Sci. 2010;65(5):621-30. doi: 10.1093/geronb/gbp112. [PubMed: 20007301].

4. Maslach C, Jackson SE. The measurement of experienced burnout. J Occup Behav. 1981;2:99-113. doi: 10.1002/job.4030020205.

5. Schufeli WB, Maslach C, Marek T. The future of burnout. Washington DC: Taylor \& Francis; 2004.

6. Karanikola MN, Papathanassoglou EE. Exploration of the burnout syndrome occurrence among mental health nurses in Cyprus. Arch Psychiatr Nurs. 2013;27(6):319-26. doi: 10.1016/j.apnu.2013.08.004. [PubMed: 24238013].

7. Salimi SH, Azadmarzabadi E, AbediDarzi M. Mental Health and Its Relationship with Job Burnout and Life Satisfaction in Staff at a Military University [in Persian]. Iran J Mil Med. 2013;14(4):289-94.

8. Yavari M, Shamsaei F, Yazdanbakhsh K. Comparison psychiatrics nurses' burnout and general health with critical care (ICU) nurses[in Persian]. J Nur Manag. 2014;3(1):55-65.

9. Merino-Tejedor E, Hontangas-Beltrán PM, Boada-Grau J, LucasMangas S. Hardiness as a moderator variable between the bigFive model and work effort. PersIndiv Differ. 2015;85:105-10. doi: 10.1016/j.paid.2015.04.044.

10. Martinez Garcia M. F. , Ramirez M. G. , Jariego I. M. . Social support and locus of control as predictors of psychological well- being in Moroccan and Peruvian immigrant women in Spain. Int J Intercult Relat. 2002;26(3):287-310. doi: 10.1016/S0147-1767(02)00005-6.

11. Charyton C, Elliott JO, Lu B, Moore JL. The impact of social support on health related quality of life in persons with epilepsy. Epilepsy Behav. 2009;16(4):640-5. doi: 10.1016/j.yebeh.2009.09.011. [PubMed: 19854111]. 
12. Chadwick KA, Collins PA. Examining the relationship between social support availability, urban center size, and self-perceived mental health of recent immigrants to Canada: a mixed-methods analysis. Soc Sci Med. 2015;128:220-30. doi: 10.1016/j.socscimed.2015.01.036. [PubMed: 25621402].

13. Cheng Y, Li X, Lou C, Sonenstein FL, Kalamar A, Jejeebhoy S, et al. The association between social support and mental health among vulnerable adolescents in five cities: findings from the study of the wellbeing of adolescents in vulnerable environments. J Adolesc Health. 2014;55(6 Suppl):31-8. doi:10.1016/j.jadohealth.2014.08.020.[PubMed: 25454000].

14. Alipor A, Sahraeian MA, Aliakbari Dehkordi M, Haji Aghababaei M. The relationship between perceived social support and hardiness with mental health of and disability status among women with Multiple Sclerosis [in Persian]. Social Psychol Res. 2011;1(3):110-33.

15. Sheard M, Golby J. Hardiness and undergraduate academic study: The moderating role of commitment. Pers Individ Dif. 2007;43(3):579-88. doi: 10.1016/j.paid.2007.01.006.

16. Bahamin GH, Taheri F, Moghaddas AR, Sohrabi F, Dortaj F. The effects of hardiness training on suicide ideation, quality of life and plasma levels of lipoprotein in patients with depressive disorder. Procedia Soc Behav Sci. 2012;46:4236-43. doi: 10.1016/j.sbspro.2012.06.233.

17. Tarimoradi A. Compares the degree of hardiness and public health between Iranian and English women university students. Procedia Soc Behav Sci. 2014;116:101-5. doi:10.1016/j.sbspro.2014.01.175.

18. Jafari E, Hajloo N, Faghani R, Khazan K. The relationship between spiritual well-being, hardiness, and mental health in the elderly [in Persian]. J Res Behav Sci. 2012;10(6):431-40.

19. Saxena $S$. Relation between psychological hardiness and mental health among college students. Indian J Health Wellbeing.
2015;6(8):823-5.

20. Tabakhnick BG, Fidell LS. Using multivariate statistics. 5 ed. Boston: Allyn \& Bocon; 2007

21. Ahghar G. The study of school organizational climate role on job stress in Tehran secondary school consultants [in Persian]. Counseling Res Develop. 2007;6(23):25-40.

22. Zimet GD, Dahlem NW, Zimet SG, Farley GK. The multidimensional scale of perceived social support. J Pers Assess. 1988;52(1):30-41. doi: 10.1207/s15327752jpa5201_2.

23. Souri A, Ashoori J. The relationship between perceived social support psychological hardiness and family communication patterns with quality of life among patients with type II diabetes [in Persian]. J Diabetes Nurs. 2015;3(2):53-65.

24. Kobasa SC. Stressful life events, personality, and health: an inquiry into hardiness. J Pers Soc Psychol. 1979;37(1):1-11. [PubMed: 458548].

25. Goldberg DP, Hillier VF. A scaled version of the General Health Questionnaire. Psychol Med. 1979;9(1):139-45. [PubMed: 424481].

26. Hajloo N. Relationship between economic-social activity and reduction of veterans' psychological problems [in Persian]. J Mil Med. 2009;11(2):89-95.

27. Memarbasi Avval M. Comparison the relationship between social sup port and coping strategies with stress, job performance and mental health among nurses of psychiatric and non-psychiatric hospital [in Persian]. Khorasan Razavi, Iran: Ferdoosi University, Faculty of Science and Psychology; 2011.

28. Najjar A. The relation Between psychological hardiness, personality traits and perceived organizational support with mental health and quality of life [in Persian]. Semnan, Iran: Islamic Azad University of Garmsar Branch, Faculty of Science and Psychology; 2016. 